Ananda Ferreira Perozzo ${ }^{1}$

(D) https://orcid.org/0000-0003-0748-2498

Antonio Egidio Nardi

Ohttps://orid.org/0000-0002-2152-4669

Cátia Maria Mathias ${ }^{3}$

Ohttps://orcid.org/0000-0002-8321-1393

Marleide da Mota Gomes ${ }^{4}$ Ohttps://orcid.org/0000-0001-8889-2573

\section{The complex relationship between neuropsychiatric disorders and infectious diseases: past, present, and the future of research}

\author{
A complexa relação entre transtornos neuropsiquiátricos e doenças \\ infecciosas: o passado, o presente e o futuro das pesquisas
}

DOI: $10.1590 / 0047-2085000000356$

\section{DEAR EDITOR,}

The current state of the COVID-19 pandemic has raised many concerns regarding indirectly and directly linked mental health disorders ${ }^{1,2}$.Fear of infection, social isolation, and economic crisis have led to globally increased psychological distress. There has been some emerging evidence of neuropsychiatric sequelae related to COVID-19 since the SARS-CoV-2 virus can infect the brain'. As a matter of fact, the relationship between infectious diseases and neuropsychiatric disorders is not a new theme of the discussion: along with history, it has been often observed and considered².

In a 1904 article, W.W. Ireland reported Ernst Siemerling's (1857-1931) shared observations that many psychotic, manic, and depressive episodes were preceded by infectious diseases such as typhoid fever, pneumonia, and mumps ${ }^{3}$. Siemerling discussed how those events seemed to be linked, and also commented that the "insanity outbreaks" preceded by infectious diseases seemed to be indistinguishable from the ones that weren't preceded by an explicit infectious malady ${ }^{3,4}$. As an example for all psychiatrists, Emil Kraepelin (1856-1926) was aware of a possible link between typhoid and scarlet fevers and psychiatric symptoms. Besides, Karl A. Menninger wrote in 1928 about how "schizophrenia syndrome" diagnosis could be a product of an infectious disease, such as influenza, for example ${ }^{5}$.

Around the time of the "Spanish Flu" pandemic of the early 20th century, encephalitis lethargica (EL) emerged and spread worldwide. Constantin von Economo (1876-1931) coined the term in 1917 and was the first to describe it more precisely, as an inflammatory disorder of the CNS marked by hypersomnolence, psychosis, catatonia, and Parkinsonism6. EL has a nonspecific prodromal phase, with influenza-like symptoms, and over months/years, the neuropsychiatric manifestations appeared, being notably similar to narcolepsy and idiopathic Parkinson's Disease ${ }^{6}$. It's a supposition never proved that influenza caused EL, and given that, there have been some concerning comparisons between EL and COVID-197.

Nowadays, there has been evidence of neurological and psychiatric burden related not only to viral and bacterial infection but also parasitic infection caused by protozoan and platyhelminths ${ }^{4}$. About research on the psychiatric field, it's interesting to mention the lack of biomarkers. It's intriguing how there is still much uncertainty about how to identify neuropsychiatric manifestations that could be related to infectious diseases ${ }^{4}$. Research on the interactions between infectious and inflammatory processes could give more insight for neuropsychiatric nosology, as well as it may bring better comprehension of etiologic aspects in CNS disorders.

Received in: Apr/5/2021. Approved in: July/24/202

1 Laboratory of Cellular Neuroanatomy, Institute of Biomedical Sciences, Federal University of Rio de Janeiro (UFRJ), Rio de Janeiro, RJ, Brazil.

2 Laboratory of History of Psychiatry, Neurology, and Mental Health, Institute of Psychiatry and School of Medicine, Federal University of Rio de Janeiro (UFRJ), Rio de Janeiro RJ, Brazil; National Academy of Medicine, Brazil; Brazilian Academy of Sciences, Rio de Janeiro, RJ, Brazil.

3 Laboratory of History of Psychiatry, Neurology, and Mental Health, Institute of Psychiatry, Federal University of Rio de Janeiro (UFRJ), Rio de Janeiro RJ, Brazil.

4 Laboratory of History of Psychiatry, Neurology, and Mental Health, Institute of Psychiatry and Institute of Neurology, Federal University of Rio de Janeiro (UFRJ), Rio de Janeiro, RJ, Brazil.

Address for correspondence: Ananda Ferreira Perozzo. E-mail: afperozzo@ufri.br 
Mental disorders emerge from a complex interplay between genetic, biochemical, psychosocial, and lifestyle factors, and a disruption in the central nervous system homeostasis caused by immune-inflammatory cascades could be one factor leading to the development of neuropsychiatric disorders ${ }^{1,2,4}$. Considering the multifactorial aspects of neurotransmitter disbalances and neuroanatomic alterations on a moremacroand/ormicro-scale, it's reasonable to call for more investigation about the consequences of inflammatory processes caused by pathogenic agents in cognition and behavior. It seems like a possibility that some given neuropsychiatric diagnoses could be better managed by treating the infection and the inflammation process. Indeed, there is the need to strengthen warning about risk factors to prevent public health neuropsychiatric events.

\section{INDIVIDUAL CONTRIBUTIONS}

Ananda Ferreira Perozzo - Drafting and finalization of the manuscript.

Antonio Egidio Nardi - Revision and finalization of the manuscript.

Cátia Maria Mathias - Revision and finalization of the manuscript.

Marleide da Mota Gomes - Revision of initial ideas and finalization of the manuscript.

\section{CONFLICTS OF INTEREST}

The authors report no conflicts of interest.

\section{REFERENCES}

1. Debnath M, Berk M, Maes M. Changing dynamics of psychoneuroimmunology during the COVID-19 pandemic. Brain Behav Immun Health. 2020;5:100096

2. Huremović D. Psychiatry of pandemics: a mental health response to infection outbreak. Gewerbestrasse: Springer; 2019.

3. Ireland WW. On Insanity After Acute and Chronic Infectious Diseases [Über Psychoses Nach Akuten Und Chronischen Infektionskrankheiten]. J Ment Sci. 1904;50(211):772-3.

4. John CC, Carabin H, Montano SM, Bangirana P, Zunt JR, Peterson PK. Global research priorities for infections that affect the nervous system. Nature. 2015;527(7578):S178-86.

5. Menninger KA. The schizophrenic syndrome as a product of acute infectious disease. Arch Neurol Psychiatry. 1928;20(3):464-81.

6. Hoffman LA, Vilensky JA. Encephalitis lethargica: 100 years after the epidemic. Brain. 2017;140(8):2246-51.

7. Giordano A, Schwarz G, Cacciaguerra L, Esposito F, Filippi M. COVID-19: can we learn from encephalitis lethargica? Lancet Neurol. 2020;19(7):570. 